\title{
De um caso clínico à pesquisa: considerações sobre a transferência na clínica da paranoia
}

From a clinical case to research: considerations on transference in clinical treatment of paranoia

De un caso clínico a la investigación: consideraciones sobre la transferencia en clínica de la paranoia

Tuliola Almeida de Souza Lima* Antônio Márcio Ribeiro Teixeira ${ }^{* *}$

\section{Resumo}

Este artigo é resultado da elaboração de uma dissertação de mestrado sobre o tema da transferência na clínica psicanalítica da psicose paranoica. Apresenta-se um caso clínico acompanhado pelos autores, considerando aspectos da teoria de Lacan, em acréscimo à formulação de Freud, a respeito da psicose e da dificuldade técnica do manejo da transferência nessa estrutura. Em seguida, abordam-se contribuições teóricas de Zenoni e Soler sobre a clínica da psicose. O método utilizado foi o de leitura teórica comentada, comparada ao observado na prática. São apresentadas conclusões sobre a postura do analista no tratamento da paranoia e o modo de manejo da transferência que o paciente paranoico desenvolve: indica-se a presença de um Outro que não vise o sujeito, um Outro retificado pelo próprio tratamento psicanalítico, que sirva como nova referência simbólica para o paciente, contribuindo assim para que ele mantenha seus laços de maneira suportável.

Palavras-chave: Clínica da paranoia, Tratamento do Outro, Manejo da transferência, Saúde mental.

\begin{abstract}
This article is a result of the elaboration of a dissertation about transference in psychoanalytic treatment of paranoid psychosis. A clinical case is analyzed by the authors considering aspects of Lacan's theory, in addition to Freud's formulation regarding psychosis and the technical difficulties of the transference manouver in this structure. Theoretical contributions by Zenoni and Soler are also analyzed. The
\end{abstract}

\footnotetext{
Mestra em Psicologia pela Universidade Federal de Minas Gerais, Programa de Pós-graduação em Psicologia. Área de concentração: Estudos Psicanalíticos. E-mail: tuliolaa@yahoo.com.br.

** Doutor em Psicanálise pela Universidade de Paris VIII, professor associado do Departamento de Psicologia da Universidade Federal de Minas Gerais. E-mail: amrteixeira@uol.com.br.
} 
method used was the commented theoretical interpretation, compared to what is observed in practice. Therefore, the conclusions presented in the article refer to the analyst's stance on the treatment of paranoia, which should indicate the presence of an Other besides the intended subject, an Other rectified by the psychoanalytic treatment, which may serve as a new symbolic reference to the patient, contributing, thus, to his or her maintenance of ties in a bearable manner.

Keywords: Psychosis clinic, Treatment of the Other, Transference Maneuver, Mental health.

\section{Resumen}

Este artículo es el resultado de la elaboración de una tesis de maestría sobre el tema de la transferencia en clínica psicoanalítica de la psicosis paranoica. Analiza un caso clínico acompañado por los presentes autores considerando aspectos de la teoría de Lacan, ampliando la formulación de Freud a respecto de la psicosis y de la dificultad técnica de la gestión de transferencia en esta estructura. En seguida, consideramos las contribuciones teóricas de Zenoni y Soler sobre clínica de la psicosis. El método utilizado fue el de la lectura teórica comentada, comparándola con la observación práctica. Se presentan conclusiones sobre la postura del analista en el tratamiento de la paranoia y el modo de gestión de la transferencia que el paciente paranoico desarrolla: se indica la presencia de un Otro que no sea el sujeto deseado, un Otro rectificado por el propio tratamiento psicoanalítico, que sirva como nueva referencia simbólica para el paciente, contribuyendo así a que mantenga sus lazos de modo soportable.

Palabras claves: Clínica de la paranoia, Tratamiento del Outro, Gestión de la transferência, Salud mental.

\section{Introdução}

C ste artigo é originado de uma dissertação, cujo problema central é o manejo da transferência no atendimento psicanalítico de pacientes paranoicos. Tal dissertação foi defendida recentemente em um Programa de Pós-graduação em Psicologia localizado em Minas Gerais.

Partindo da apresentação sucinta de um caso clínico de paranoia, abordamos a teorização sobre a constituição psíquica nesse tipo clínico, destacando a predominância do imaginário e da deslocalização pulsional - real - observados na prática. 
O problema da transferência na paranoia decorre do fato de o paranoico ser orientado por sua convicção delirante de ser objeto de interesse do Outro; ele sofre o assédio desse Outro. Quando comparada com outros tipos de psicose, pode-se afirmar que, na paranoia, o Outro de fato existe. A sua (des)organização libidinal, como vítima do Outro, interfere nas possibilidades de se desenvolver um tratamento.

Apesar da dificuldade, não deixamos de tentar conduzir um tratamento psicanalítico em casos de paranoia. Um objetivo deste, então, consiste em retificar esse lugar da alteridade, uma vez que o paranoico em si não pode ser retificado. É o oposto da retificação subjetiva que encontramos nos casos de neurose.

Consideramos de saída os trabalhos de Freud (1916-1917/1996) a respeito da organização libidinal na paranoia, que conduzem a uma reflexão sobre o modo como o laço social do paranoico é feito.

Naquele momento o autor formulou a hipótese de que o principal fato nas psicoses graves (as quais entendemos como crises com alucinaçôes e delírios) é as pulsões do eu terem "perdido sua orientação" (Freud, 19161917/1996, p. 430). Após o surto, o investimento libidinal se mostra de fato comprometido; o que anteriormente investia o eu fica então desnorteado. A identificação do sujeito, extremamente fragilizada, perturba-se e dificulta a relação com os outros, relação que depende também de um investimento de energia determinado.

Pela releitura do texto de Freud, considerando esclarecimentos feitos por Lacan, poderemos ver como é possível fundamentar considerações sobre o manejo da transferência, por meio de uma série de constatações extraídas da clínica com a psicose.

\section{Apresentação do caso clínico}

Nosso interesse específico sobre o manejo da transferência na paranoia surgiu durante o atendimento de uma paciente, de nome fictício Cláudia, em um ambulatório de psiquiatria (o que durou aproximadamente dois anos). Tratava-se de uma mulher de 46 anos, casada, mãe de três filhos, que se queixava de estar sendo perseguida pela esposa de um primo seu. Esse casal residia no exterior, mas, mesmo assim, segundo relatado em atendimento, a mulher conseguia influenciar negativamente a paciente aqui no Brasil.

A história clínica, investigada ao longo de todo o atendimento, indicava o começo da perseguição como uma reação de ciúme da mulher citada: 
muitos anos antes, após um telefonema feito para esse primo, para uma conversa fraterna, essa mulher começou a agir contra a paciente, incitando seus conhecidos a perturbar-lhe. A queixa, no primeiro momento, era sobre uma quantidade extraordinária de telefonemas recebidos, em sua casa, dos quais Cláudia anotava o número de origem da ligação, o local e o horário, para descobrir quem havia ligado. Tal ocorrência apresentava para ela um problema de pressão que ela estava vivendo.

Além desses telefonemas, havia sofrido uma invasão em uma casa de sua propriedade, seu computador e celular estragavam; tudo isso sendo de responsabilidade da perseguidora. Os sinais estranhos percebidos em seu cotidiano eram exaustivamente decifrados, em uma compulsão à interpretação característica da psicose paranoica.

Sobre a pressão citada, foi particularmente curioso, já no primeiro atendimento, isto ter sido mencionado após a pergunta de alguma vez ela ter sofrido de depressão. Pois isso demonstra um tratamento peculiar dado à palavra, na qual esta é carregada de uma significação intensa, no entanto obscura, e sem o mesmo significado corrente atribuído no contexto social mais geral. A psicose, naquele momento, caracterizava-se pela localização de signos que diziam respeito à paciente, embora ela ainda não tivesse precisado o que estavam querendo dela.

Apesar de estar precavida das especificidades da transferência na psicose, a psicóloga acabou ocupando, então, um lugar de aparente passividade, dispondo-se, na maior parte do tempo, a ouvir as produçóes delirantes, claramente persecutórias, de Cláudia.

Se, no começo do tratamento, ela estava impedida de realizar suas atividades diárias, devido às ações que sofria por parte de sua perseguidora, depois de um tempo, porém, ela começou a retomá-las aos poucos, passando também a declarar-se mais tranquila, apesar das intenções maldosas de outras pessoas do seu convívio. O delírio, por sua vez, alterou-se ao longo dos atendimentos para uma conformação mais erotomaníaca: em vez de a fala de Cláudia destacar o que a mulher perseguidora fazia, ela passou a tratar do seu amor pelo marido dessa mesma mulher, seu primo. Um amor que ela lhe dedicava por estar certa do sentimento dele, ao qual ela respondia, portanto, secundariamente.

Uma dose relativamente pequena de antipsicótico foi prescrita, do qual a paciente fez uso durante o tratamento, apesar de alguma resistência sua a utilizá-lo, a princípio. Ao fármaco, foi aliada a escuta das elaboraçôes sempre verossímeis, mas baseadas na interpretação delirante, ora a de ser visada pela perseguidora, ora de ser amada pelo primo. 
Ao final do período do acompanhamento de Cláudia, parecia que seu objetivo maior era esperar o reencontro com esse indivíduo, de quem ela decifrava as mensagens enviadas anonimamente por diversos meios virtuais; ou seja, ela tinha certeza de que era ele o remetente apaixonado.

No caso, pôde ser destacada a função organizadora que essa espera pareceu representar, de modo que a paciente chegou a uma espécie de estabilização. Isso ocorreu, talvez, mais por causa dos seus recursos do que em função de uma ação específica do tratamento, nos atendimentos no ambulatório. No entanto, a possibilidade de passarmos a compor seu delírio persecutório era considerada, derivando daí o interesse em estudar mais a fundo as características do tratamento da psicose, a fim de nos orientarmos melhor nessa prática.

\section{Os excessos da constituição psíquica na paranoia}

O tratamento de pacientes paranoicos conduz ao problema de como o analista pode agir para não impedir uma instauração e manutenção da transferência, visando a obter efeitos de apaziguamento para o sujeito. Devido ao fato de as soluçóes para as crises delirantes originarem-se dos arranjos feitos pelos próprios pacientes, a constituição psíquica, notadamente no ponto em que ela se refere ao imaginário, é fundamental para se pensar como a direção do tratamento pode adequar-se a esse tipo de arranjo.

Dada a sua estruturação típica, é possível notar, de fato, como a relação do sujeito com a alteridade simbólica se torna problemática em seus diversos relacionamentos. Utilizamos como referência teórica e prática o primeiro momento da teoria lacaniana, na qual a estrutura psicótica, por oposição à neurótica, baseia-se na não incidência da função paterna no par primordial formado pelo sujeito e sua mãe, a primeira figura do Outro.

A relação do sujeito em constituição é ilustrada pelo esquema L de Lacan (1954-1955/1985), que permite uma leitura do fenômeno psicótico como uma confusão incessante entre o outro do registro imaginário e o Outro do simbólico, já que o eixo simbólico não interveio em tempo hábil como um regulador da relação imaginária. Se a constituição imaginária é indispensável para a subjetividade, ela requer, no entanto, que uma ordenação incida sobre ela, deixando ao sujeito a possibilidade de senti-la como algo falsificável. 
Figura 1 - Esquema L

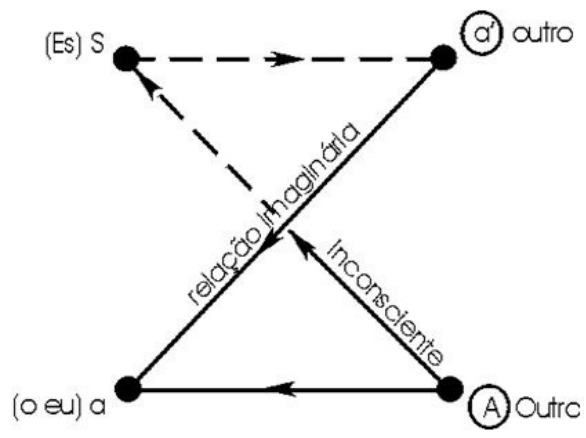

Fonte: Lacan, 1954-1955/1985a, p. 142

No caso da psicose, admitimos como hipótese que o eixo que atravessa a relação imaginária não se sustenta, ficando instável e denotando uma ausência da regulação simbólica. Essa leitura do esquema sugere onde houve falha, na psicose.

A foraclusão do Nome-do-Pai (Lacan, 1955-1956/1985) não implica, necessariamente, em um desencadeamento psicótico, pois o sujeito pode funcionar utilizando outros recursos, como uma solução imaginária, ou uma identificação pautada sobre um duplo especular. Sabemos que essas soluções, que se situam no eixo imaginário do esquema L, evidenciam fenômenos de transitivismo, nos quais encontramos com frequência aspectos agressivos e erotomaníacos.

O caso clássico de Schreber, analisado literariamente por Freud (1911/1996) e retomado por Lacan (1955-1956/1985b), é paradigmático da loucura paranoica, na qual uma fixação no registro imaginário é evidente. Uma ideia crucial no adoecimento de Schreber é o pensamento sobre como seria belo ser uma mulher no momento do coito (que influenciou toda a construção delirante em seu caso). Freud destacou, sobre a relação de Schreber com seu médico, que o paciente tomou uma atitude feminina em relação a Flechsig, relacionada ao desejo de Schreber implícito no pensamento mencionado; com isso, teria sido em função dessa "manifestação de libido homossexual" (Freud, 1911/1996, p. 52) que a doença teria se manifestado, com o intuito de defender o eu de Schreber.

O caso demonstra uma dificuldade inerente à clínica da paranoia, devido ao risco do aumento da produtividade delirante do paciente, na qual o próprio médico pode ser inserido, e também o aumento dos riscos de passagem ao ato por parte do sujeito. Tal como explicitado em suas memórias, Schreber 
(1903/1995) revela a posição assumida por Flechsig em seu tratamento: o fato de o médico interessar-se pelo seu corpo, para estudos científicos diversos, era fonte de extrema angústia durante todo o tempo em que esteve internado para tratar-se. O modo de relação de Schreber com Flechsig indica a lógica da manifestação da transferência na paranoia.

Através do seu esquema I, Lacan localiza os elementos do delírio de Schreber, bem como a solução deste de se tornar "A mulher de Deus para gerar uma nova raça de homens":

Figura 2 - Esquema I

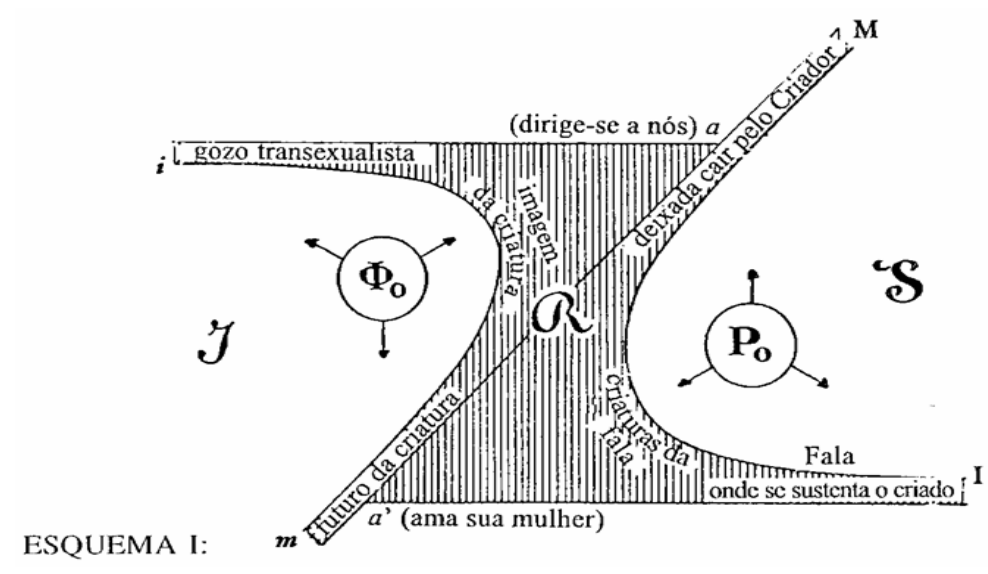

Fonte: Lacan, 1957-1958/1998, p. 578.

Alocalização do ideal delirante e sua relação com o fenômeno da transferência (ou seja, a invenção de Schreber que o permite restabelecer seus laços após a doença nervosa, em alguma medida) é demonstrada no esquema, assim como o modo de investimento paranoico sobre um determinado significante.

O esquema I é então o resultado da análise de Lacan (1957-1958/1998) sobre o caso Schreber, e representa uma formalização da solução encontrada pelo último. Os eixos indicam como o delírio permitiu um efeito de estabilização à proporção que uma hipérbole pôde ser construída, conformando a diretriz assintótica do delírio. No gráfico, nota-se "o vínculo tornado sensível, na dupla assíntota que une o eu delirante ao outro divino", além da referida "divergência imaginária no espaço e no tempo com a convergência ideal de sua conjunção" (Lacan, 1957-1958/1998, p. 578). A promessa de emasculação de Schreber foi se adiando, até o infinito, o que não é sem relação com a sua miragem 
delirante. Nesse mesmo sentido, Lacan aponta a ausência de mediação entre o sujeito e a fantasia desenvolvida, já que a postergação ocorreu concretamente.

Desse modo, se nos ativermos ao exemplo de Schreber, podemos pensar na função do analista, colocado em posição de ideal, como um ponto capaz de sustentar a invenção do sujeito. Trata-se de um aprendizado sobre a solução encontrada pelo sujeito por sua conta, pois sabemos que não houve contato dele com a psicanálise. Esse ponto do esquema pode ser entendido como aquele que supre o buraco simbólico causado pela foraclusão do Nome-doPai.

Por essa leitura, consideramos a hipótese de que, no tratamento, o analista transita entre a posição de testemunho e a posição representada por um significante tomado pelo sujeito como um ideal. Diante da consideração do furo na estrutura psicótica, o analista permitiria, assim, ajudar a estruturar a solução de um determinado psicótico que estivesse em análise (Soler, 1989). Mas voltaremos mais adiante ao papel do analista no tratamento da psicose paranoica.

Já o caso de Aimée, apresentado por Lacan (1932/1987) em sua tese de doutorado, é indicativo da produção delirante para a organização de um determinado sujeito. Ele fornece uma ilustração a respeito da passagem ao ato na psicose: tomada por sua convicção delirante de ser perseguida por uma famosa atriz onde vivia, Aimée foi ao teatro onde a atriz iria se apresentar, agredindo-a subitamente, sendo detida e levada, por isso, ao serviço de psiquiatria.

Relendo o caso sob a ótica da teoria psicanalítica desenvolvida posteriormente, pode-se conceber esse ato como uma tentativa de separar algo insuportável que liga o sujeito psicótico ao Outro. É precisamente a falta de mediação simbólica em sua vivência o que provoca a confusão entre seus próximos, afetando esse estatuto da alteridade tão evidenciado em um delírio, como o de perseguiçãa.

$\mathrm{Na}$ passagem ao ato, há um excesso a ser subtraído da economia psíquica de um paciente psicótico (Guerra, 2007). Ela representa um modo de agir determinado por uma invasão do registro real, em consequência da carência simbólica na estrutura em questão. Os momentos de crise dos diferentes casos indicam o risco iminente dessa ação, muitas vezes ligada ao delírio desenvolvido.

Convém destacarmos outro momento da formulação de Lacan particularmente importante para nossa concepção sobre a paranoia: trata- 
se da noção de sujeito do gozo, para caracterizar o psicótico. Com isso, Schreber pode ser considerado como o exemplo mais contundente do sujeito submetido ao gozo do Outro (Lacan, 1966/2003), devido à não extração do objeto $a$. Essa noção representa mais um esclarecimento à teoria estruturalista da psicose.

O objeto a é o construto lógico que determina o estatuto da realidade para um sujeito, que depende de sua localização para modelar aquilo que ele compartilha socialmente.

\section{O problema da transferência, vínculo libidinal}

Consideramos então que a consequência da estruturação psicótica na transferência é justamente a condição de que, não tendo passado pela castração (ou seja, não tendo sido extraído o objeto $a$ do sujeito), o paranoico vive como aquele que porta de fato o objeto causa de desejo do Outro. Por vezes o sujeito tenta se distanciar desse objeto que ele mesmo porta, no intuito de deixar de ser alvo do Outro de maneira insuportável.

Assim, o vetor da transferência que, na neurose, dirige-se do sujeito ao Outro (representado pelo analista no tratamento) já que o sujeito localiza no Outro o objeto $a$; tal vetor, no caso da psicose paranoica, dirige-se ao contrário, do Outro ao sujeito (Zenoni, 2007).

O problema envolve o estatuto do Outro, que acaba sendo tomado como outro, semelhante, com a predominância do eixo imaginário não regulado pelo simbólico. Se, por um lado, essa disposição imaginária pode facilitar a adesão do paranoico ao tratamento, permitindo a relação transferencial; por outro, podemos admitir a fragilidade dessa relação. É essa disposição baseada no imaginário o que, ao mesmo tempo, remete-nos à dificuldade clínica do manejo. A questão envolve como ocupar o lugar do outro, sem se basear no registro especular, tampouco sem passar por um Outro absoluto; pois a concepção paranoica daquele que ocupa o lugar da alteridade é uma posição tomada sem dialética.

Sobre a atribuição de saber, comumente suposta ao analista em casos de neurose, o paciente paranoico é, diferentemente, aquele que sabe sobre si; ele não supõe saber ao Outro. Sua condição o impele, por vezes, a ter certeza quando o outro sabe ou quer algo dele (certeza, sem dúvida, pautada por um delírio, e que impede o próprio tratamento).

Como o psicótico não situa o Outro como interditado, marcado por uma falta, a clínica com a psicose baseia-se nessa dificuldade. Sabendo do lugar 
em que o psicanalista é colocado pelo modo da estruturação paranoica, o problema da transferência é como responder a ele sem que nos encaixemos nas formulações delirantes e encarnemos a posição do Outro que o visa constantemente.

\section{Modos de manejo da transferência na paranoia}

Alguns autores que utilizam a teoria freudiana e lacaniana como referência têm articulado a ela a experiência clínica com a psicose. Nesse sentido, os trabalhos de Alfredo Zenoni (2000; 2007) e Colette Soler (1989; 2007), por exemplo, são bastante ilustrativos da especificidade da clínica com paranoicos. Zenoni (2007) aborda a orientação que o profissional deve ter quando diante da transferência psicótica, que se caracteriza principalmente pela certeza do paciente de concernir, ele mesmo, ao Outro com quem convive. Para o autor, há consideraçôes generalizáveis que a prática com psicóticos permite difundir, compondo atitudes que orientam o próprio analista a manejar esse tipo de transferência.

Podemos estabelecer os principais modos de manejo, que incluem o silêncio por parte do analista, no sentido de ele se abster de demonstrar qualquer vontade a respeito do paciente; e um cuidado com a palavra, evitando dizeres que tenham claramente duplo sentido, ou algo implícito ou vago em seu enunciado; de onde se chega à conclusão evidente da não recomendação de uma prática interpretativa na clínica da paranoia.

Destaca-se, também, de um modo que se aproxima desses cuidados indicados, como uma "retificação do Outro" se mostra particularmente eficaz no tratamento da paranoia, já que o gozo é localizado no Outro. Tal expressão, encontrada na obra de Soler (1989), indica como o analista, uma vez advertido dos riscos inerentes ao tratamento da psicose paranoica, pode propiciar um novo espaço de endereçamento das produções do paciente, retificando a alteridade indiscreta que, no momento de crise, ameaça-o incessantemente.

$\mathrm{Na}$ falta da metáfora paterna na estruturação do paranoico, a retificação do Outro (do analista) pretende introduzir nele, para compensar tal falta, uma regulação que teria sido alcançada com o Nome-do-Pai operante. Seria como se esse novo Outro pudesse fazer as vezes das ausências simbólicas constitutivas. A retificação possibilita, portanto, um saber que possa operar sobre o real, e tenta assim suprir a ausência da falta subjetiva.

A partir dos casos mencionados, podemos concluir que uma organização ou contenção da crise, baseadas com frequência em diversos pressupostos 
delirantes, permite uma vivência mais ou menos apaziguada, que representa a própria fase de estabilização. A função que o manejo da transferência adquire passa a ser que cada paciente construa um novo modo de articular os registros (imaginário, simbólico e real) em sua experiência.

Uma conclusão sobre o laço do paciente paranoico com o analista, com a ocorrência do tratamento, pode ser resumida nos seguintes termos: o Outro, encarnado pelo analista o mais próximo possível do registro simbólico, passa a ser um Outro tratado, retificado, passando a encarnar uma nova referência simbólica para o paciente. Por meio de suas elaborações, ainda que envolvidas pelo delírio, o imaginário vai sendo delimitado, de modo que ele pode assumir limites compatíveis com sua inserção social; daí se presume a capacidade de alguma ordenação do gozo, uma vez que o investimento libidinal passa a ser direcionado para um ponto específico, de preferência sem uma aderência extrema do sujeito ao significante escolhido por ele, com o qual ele se identifica e pelo qual se posiciona no mundo. $\mathrm{O}$ ponto do real seria então circunscrito de maneira a não precipitar o sujeito em uma passagem ao ato grave.

O manejo da transferência na paranoia, levando em conta a especificidade dessefenômeno como respostaestrutural, econsiderando aindaassingularidades de cada caso, contribui para uma elaboração de suas experiências de modo a possibilitar que se alcance uma distância justa entre o sujeito e o Outro; o que representa uma espécie de localização suportável do investimento libidinal entre o sujeito e os diversos objetos de seu mundo.

\section{Conclusão: o tratamento da paranoia no âmbito institucional}

Atualmente psicanalistas de orientação teórica lacaniana trabalham com a psicose, não só em consultórios particulares, mas também em instituições de assistência à saúde mental. A instituição, em que trabalha uma equipe variada responsável pelo paciente, representa a chance de se fazer tanto uma regulação do Outro quanto uma pluralização deste. O ponto teórico de convergência entre a clínica que se faz em consultórios e o acompanhamento por uma equipe nos é fornecido por Zenoni (2007), ao identificar a instituição, com seu tratamento feito por muitos, como um novo Outro. Isso se assemelha à proposta de Soler (1989) do Outro da paranoia poder mostrar-se retificado, em comparação com o que o sujeito vivencia em outros círculos, ou com o que experimenta em um momento de crise.

Há ainda uma consideração a ser feita sobre o caso de Cláudia: ela definiu um ponto pelo qual esperar, demorasse o tempo que fosse. A paciente encontrou um modo de colocar o pulsional a distância, ao manter-se atenta 
aos sinais relativamente misteriosos de seu primo que, apesar de longe, não lhe deixava dúvidas de que viria um dia ficar com ela. Esse tipo de saída é delimitado, conforme visto também em outros casos, pelo próprio sujeito. $\mathrm{O}$ psicanalista teria a função, entre outras, de ser uma testemunha da elaboração alcançada, favorecendo, ao mesmo tempo, a delimitação de um modo de regulação do investimento libidinal do sujeito.

Outro aspecto a ser considerado no caso, para que o tratamento fosse bem sucedido, é o atendimento ambulatorial ter sido feito por mais de um clínico, já que nele havia alguém da psicologia e o médico psiquiatra. É notável como essa estrutura de atendimento, claramente triangulada, favorece a manutenção da transferência, ao evitar uma relação concreta e maciça somente entre duas pessoas.

A despeito das recomendações técnicas que podemos estabelecer de modo geral, a dificuldade do atendimento psicanalítico permanece como lidar com as particularidades dos casos, precisando-se averiguar em cada um deles o modo como o sujeito se relaciona com o Outro e como ele encontra recursos para elaborar suas experiências, podendo assim estabelecer e manter seus laços.

\section{Referências}

Freud, S. (1996). Notas psicanalíticas sobre um relato autobiográfico de um caso de paranoia (dementia paranoides). In S. Freud. Edição standard das obras psicológicas completas de Sigmund Freud (Vol. 12, pp. 23-104). Rio de Janeiro: Imago. (Texto original publicado em 1911)

Freud, S. (1996). Conferência XXVI : a teoria da libido e o narcisismo. In S. Freud. Edição standard das obras psicológicas completas de Sigmund Freud (Vol. 16, pp. 481-502). Rio de Janeiro: Imago. (Texto original publicado em 1916-1917)

Guerra, A. (2007). A estabilização psicótica na perspectiva borromeana: criação e suplência. Tese de doutorado. Universidade Federal do Rio de Janeiro, Rio de Janeiro.

Lacan, J. (1987). Da psicose paranoica em suas relaçôes com a personalidade. Rio de Janeiro: Forense Universitária. (Texto original publicado em 1932)

Lacan, J. (1998) Escritos. Rio de Janeiro: Jorge Zahar. (Texto original publicado em 1966) 
Lacan, J. (1985). O Seminário - livro 2: o eu na teoria de Freud e na técnica da psicanálise. Rio de Janeiro: Jorge Zahar. (Texto original publicado em 19541955)

Lacan, J. (1985). O Seminário - livro 3: as psicoses. Rio de Janeiro: Jorge Zahar Editor. (Texto original publicado em 1955-1956)

Lacan, J. (2003). Apresentação das Memórias de um doente dos nervos. In J. Lacan. Outros escritos. Rio de Janeiro: Jorge Zahar. (Texto original publicado em 1966)

Schreber, D. P. (1995). Memórias de um doente dos nervos. Rio de Janeiro: Graal. (Texto original publicado em 1903)

Soler, C. (1989). Estudios sobre la psicosis. Buenos Aires: Ediciones Manantial.

Soler, C. (2007). O inconsciente a céu aberto da psicose. Rio de Janeiro: Jorge Zahar.

Zenoni, A. (2000). Qual instituição para o sujeito psicótico? Abrecampos: Revista de Saúde Mental do Instituto Raul Soares, 1 (0), 12-31.

Zenoni, A. (2007). Comments'orienter dans le transfert. Revista Digital Clinicaps, (1). Recuperado em 4 de setembro, 2008, de http://www.clinicaps. com.br/clinicaps_revista_01_edit.html. 